\title{
Noise and the City: Leveraging crowdsourced big data to examine the spatio- temporal relationship between urban development and noise annoyance
}

\author{
Hong, Andy ${ }^{* \dagger}$, Kim, Byoungjun, Widener, Michael
}

\begin{abstract}
Noise is one of the most frequently complained nuisances and public health hazards. While traffic-related noise has been studied extensively, research on construction noise has been lacking. In this study, we examined the relationship between construction activities and noise annoyance and tested whether this relationship is stronger during after-hours. Data were drawn from a historical inventory of major development projects and crowdsourced citizen complaints data (311 calls) in Vancouver, Canada from 2011 to 2016. Mixed effects models were developed with an interaction between construction activities and after-hours report. Results show that neighborhood noise complaints were significantly associated with major constructions $(\mathrm{IRR}=1.062,95 \% \mathrm{CI}=1.024-1.097)$. A significant interaction effect was also found between construction activities and after-hours reporting (IRR $=$ $1.050 \mathrm{CI}=1.012-1.087$ ). To our knowledge, this is one of the first studies to empirically show adverse effects of urban development on noise annoyance. Results imply that existing noise bylaws may not be effective in restricting construction activities at night and during sleeping hours that may cause adverse health effects.
\end{abstract}

Keywords: noise; annoyance; 311; big data; constituent relationship management (CRM); construction; crowdsourcing; smart cities

\section{Highlights:}

- Demonstrated a novel use of crowdsourced big data for noise research

- Construction activities were positively associated with noise complaints

- Construction's impact on noise annoyance may be stronger during after-hours

- Noise bylaws should be amended to restrict after-hours construction

\footnotetext{
* This paper is currently under review in Environment and Planning B. Please do not circulate without the authors' consent.

${ }^{\dagger}$ Corresponding author: The George Institute for Global Health, Nuffield Department of Women's \& Reproductive Health, University of Oxford, Hayes House, 75 George Street, Oxford, OX1 2BQ, United Kingdom E-mail address: andyhong@gmail.com, andy.hong@georgeinstitute.ox.ac.uk (Andy Hong).
} 


\section{INTRODUCTION}

3 Noise is one of the most hazardous environmental pollutants in urban areas. Studies showed that

4 approximately $40 \%$ of urban residents in the European Union was exposed to excessive noise

5 ( $>55 \mathrm{~dB})$ daily (Berglund et al., 1999). In the United States, more than 100 million people were

6 exposed to noise that was high enough to introduce negative health outcomes (Simpson and

7 Bruce, 1981; US EPA, 1981). A. A growing body of literature has reported a link between

8 chronic exposure to noise and adverse effects on auditory health as well as psychological, behavioral, and physical health (Basner et al., 2014; Ising and Kruppa, 2004; Passchier-Vermeer and Passchier, 2000; Stansfeld et al., 2000). Because of these negative health impacts, environmental noise has emerged as one of the most important topics in public health (Adams et al., 2006; Hammer et al., 2013; Wandersman and Nation, 1998). Noise is also a common cause of neighbor disputes, potentially leading to verbal, psychological, and even physical conflicts between neighbors (The Atlantic, 2018). Popular media often portray noise pollution as one of the top urban issues causing public anger and frustration (Lovgreen, 2017; The Canadian Press, 2016).

Prior research on urban noise tends to focus on traffic noise, such as noise from vehicular traffic (Jakovljevic et al., 2009), aircraft (Lawton and Fujiwara, 2016), and railroads (Knall and Schuemer, 1983). Recio et al (2016) found that long-term as well as short-term road traffic noise is associated with cardiovascular, respiratory, and metabolic health. Orban et al (2016) also found that traffic noise in residential areas increases the risk of depressive symptoms. Pathak et al (2008) reported a significant association between traffic noise and negative impacts on daily activities, such as resting, reading, and communication. A number of studies have reported a relationship between airport noise and sleep disturbance (Basner et al., 2006), cardiovascular disease (Davies and Van Kamp, 2012; Eriksson et al., 2014; Jarup et al., 2005; Schmidt et al., 2013), and mental health (Beutel et al., 2016; Schreckenberg et al., 2010). Additionally, a small number of studies looked at the relationship between railroads and health impacts (Saremi et al., 2008; Sørensen et al., 2011). More broadly, noise annoyance has been negatively linked to selfreported health (Hammersen et al., 2016) and wellbeing (Shepherd et al., 2010). 
32 Although traffic noise has been studied extensively, research on other sub-chronic noise 33 pollutions, such as noise from nearby neighbors and construction activities, has been lacking.

34 Especially in rapidly growing cities, one of the biggest noise annoyances in urban areas may 35 come from construction activities ( $\mathrm{Ng}, 2000)$. Construction, or more broadly speaking, urban 36 development, is generally a sign of a healthy economy; however, rapid urban development may 37 sometimes negatively impact human health, especially for the poor (Dye, 2008). From a classic 38 environmental economics perspective, construction noise may be considered a negative externality, which is not fully internalized in most cost-benefit analysis frameworks (de Hollander and Staatsen, 2003).

42 Compared to consistent noise generated by traffic movement, frequency and levels of construction-related noise may change throughout the day, and therefore, are difficult to capture and quantify. For this reason, most research on noise pollution has typically focused on objective measurement, such as A-weighted sound pressure level $\left(L_{A e q}\right)$. However, the level of noise annoyance and disturbance may vary by people's characteristics (Belojević et al., 1997), social and cultural factors (Hall et al., 2013), and different times of day (Hoeger et al., 2002). People may also perceive noise pollution differently depending on their sensitivity to noise (Ohrström et al., 1988; Shepherd et al., 2010). However, few empirical research exist to date that examines perceived noise annoyance and disturbance due to construction activities prevalent in rapidly

51 growing cities.

53 Given the paucity of research on perceived noise annoyance with respect to construction, this 54 study investigates the relationship between construction and noise annoyance, and whether after55 hours reporting moderates this relationship. Our analysis is based on crowdsourced noise 56 complaints extracted from the 311 system that archives residents' service requests or complaints.

57 The use of crowdsourced citizen complaint data as a proxy for noise annoyance is novel. To our

58 knowledge, this is one of the first studies to empirically show adverse effects of urban 59 development on perceived noise annoyance, which may be linked to successful urban planning 60 and resident wellbeing (Shepherd et al., 2010). 


\section{METHODS}

\subsection{Study area}

This study was conducted in the City of Vancouver, British Columbia, Canada. Vancouver is the

67 eighth largest Canadian city with population of 631,486 (Statistics Canada, 2017) and one of the fastest growing cities in Canada. The number of building permits issued by the City and the construction values have been steadily increasing every year since 2011 (Figure S6a). The average number of new permits issued is 5,731 cases per year, and the average construction value is about $\$ 2.18$ billion (cdn.) per year. While more than half of these permits are for residential home development, around 20 to 30 cases per year since 2011 valued at $\$ 20$ million (cdn.) or greater are very large construction projects (both commercial and residential development) (Province of British Columbia, 2017).

\subsection{Crowdsourced noise complaints}

77 The main outcome variable is noise complaints extracted from approximately two million geocoded 311 service requests in the City of Vancouver from 2011 to 2016 (City of Vancouver,

79 2017b). The 311 system is a centralized a 24/7 non-emergency telephone service and online platform where residents can file complaints or requests on various issues. The 311 system

81 records every instance of citizen reports which include date, time, request handling department

82 and division, as well as case types and approximate location of the reporting individuals. Noise 83 complaints account for about 2 to $3 \%$ of the entire service volume, while the most frequently

84 reported cases are related to garbage and yard trimming pickups, and street tree and street light

85 issues. In 2008, the City of Vancouver implemented a phone-based 311 system and launched

86 VanConnect in 2015, an app that allows citizens to report complaints and submit service requests

87 via their smart phones. Noise complaints have been increasing steadily since 2011, and no

88 apparent surge in number of reports has been identified after the implementation of the smartphone app in 2015 (Figure S6b).

91 After-hours reporting

92 After-hours noise complaints have accounted for more than $40 \%$ of all the noise complaints

93 consistently throughout the year (Figure S6b). This is notable because the City of Vancouver has 
94 had noise bylaws for more than three decades, aimed at limiting construction activities to

22 restricted day-time hours. According to the City of Vancouver's Noise Control Bylaw 6555 (City of Vancouver, 2016), the permitted hours for construction activities are 7:30am - 8pm (MondayFriday) and 10am - 8pm (Saturday) for private properties; and 7:30am - 8pm (Monday-Saturday) and 10am - 8pm (Sunday and holidays) for city streets. However, developers can bypass these restrictions by applying for a noise bylaw exception permit for a small fee (\$165-329, cdn.). To test the effect of after-hours reporting, we created a dummy variable to indicate whether the noise complaints were recorded during the after-hours. We then included the interaction term between the after-hours reporting and the construction activities in the mixed effects models.

\section{Quality assurance of the crowdsourced 311 data}

Because 311 data are relatively new in noise research, we examined the quality of the data to ensure that the data are a valid signal of noise annoyance. Noise complaint data were extracted by classifying "Noise Complaint Case" and "General Noise Inquiry Case" on "Case Type" column of the original 311 dataset. First, the total 311 call volumes were calculated by year, and other complaints and service requests were compared against noise complaints. The total volume of 311 cases were increased over time, and only noise complaints showed a clear increasing pattern over time (Figure S1). This confirms that the trends observed in the noise complaints may not be driven by internal systematic changes in the 311 system or other secular trends that may endogenously affect noise complaints. Secondly, we checked to see if there were any instances of repeat submissions from the same address, e.g. super users. The data source could be subject to a "squeaky wheel" problem where excessive noise complaints come from a few people highly sensitive to noise, and these potential outliers may introduce bias in the data. However, close analysis of super users revealed that less than $1 \%$ of repeat noise complaints ( $>5$ times / month) came from the same addresses, and only four extreme cases from the same addresses $(>10$ times / month) were identified (Figure S2). Also, our analysis results remained robust after removing these outliers from the sample. This suggests that our results are less likely to be influenced by a few outliers. 


\subsection{Major project inventory (MPI)}

126 Our key predictor variable is the count of large-scale construction activities from 2011 to 2016

127 obtained from the major project inventory (MPI) database. The MPI database is maintained by

128 the Province of British Columbia and includes a listing of both private and public sector construction projects with an estimated capital cost of \$15 million (Cdn.) or greater. Within the lower mainland area, which includes our study area, the MPI captures construction projects that are valued at \$20 million (Cdn.) or greater. For example, the major projects can range from as small as a 10-story condominium building to as big as a hospital redevelopment project. New projects are updated every quarter, and projects are removed from the list when they are completed or on hold for more than two years. For the purpose of our analysis, each project was coded as a dummy variable, with 1 indicating projects either started or are ongoing, and 0 indicating projects completed or on hold for each quarterly update.

\subsection{Covariates}

139 Census measures. As control variables, key demographic and socioeconomic characteristics were 140 obtained from the Canada 2016 Census. Our unit of analysis is dissemination area, the smallest 141 standard geographic area with a population of 400 to 700 persons defined by Statistics Canada. It 142 is comparable to the U.S. Census block group. Typical demographic and socioeconomic controls 143 were included in the final models, such as population size per dissemination area, proportion of 144 children under 15 years, proportion of seniors over 65 years, proportion of houses rented, 145 employment rate, and median household income. These covariates are included to help explore 146 whether dissemination areas with particular populations are more sensitive to noise annoyance.

147 For example, dissemination areas with large portions of older or unemployed adults may have a 148 larger number of potential reporters at home during times when construction activities are 149 permitted.

151 Political participation. In addition to the demographic and socioeconomic controls, we further 152 included voting rates as a proxy measure for political participation. Previous studies using data 153 from constituent relationship management (CRM) system (e.g. 311 calla) have reported that 154 there may be systematic biases in measurement due to some aspects of data collection, resulting 155 in skewed reporting in the 311 system across neighborhoods (O’Brien et al., 2015, 2016; 
156 Offenhuber, 2015). For example, O’Brien and his colleagues (2016) have reported that civic

157 activities and voting predicted a greater likelihood of reporting neighborhood disorder. To

158 account for potential confounding effect of political participation, we used the most recent

159 municipal election data from the City of Vancouver (2017a). Because voter turnout in local

160 elections tends to be very low during non-federal elections, participation in municipal election

161 has been regarded as an effective measure of political participation (Hajnal and Lewis, 2003;

162 O'Brien et al., 2016). Figure S3 show the geographic distribution of municipal voting rates in

1632017.

164

165

Number of proximate eating and drinking places. Another potential confounder of construction-

166 related noise in urban areas includes proximity to noisy restaurants, bars, and nightclubs.

167 Residents living in mixed use developments where shops and restaurants are collocated with

168 residential units in the same building are particularly vulnerable to noise because these

169 businesses are usually open until late at night. We used 2016 enhanced points of interest (EPOI)

170 data from DMTI CanMap to extract businesses related to eating and drinking using Standard

171 Industrial Classification (SIC) codes, 5812 and 5813 (Industry Group 581: Eating And Drinking

172 Places) (DMTI, 2016). Geographic distribution of these businesses shows that they are mostly

173 concentrated in downtown and along major corridors (Figure S4).

174

175 Residential exposure to transportation noise. To account for the effect of transportation noise,

176 we included all transportation-related noise in the regression models. Detailed methods for

177 estimating transportation noise have been described elsewhere (Gan et al, 2012). In brief, the

178 noise prediction software CadnaA (Datakustik, Greifenberg, Germany) was used to estimate

179 integrated transportation-related noise levels during the day, evening, and night in Vancouver for

180 the year 2003. The data were based on estimated road traffic data, railway noise data, and aircraft

181 noise data, and were calculated as annual day-evening-night A-weighted equivalent continuous

182 noise levels $\left(L_{d e n} \mathrm{~dB}(\mathrm{~A})\right)$ for each area covered by a 6-digit postal code. The postal code-level data

183 were then aggregated at the dissemination area level to be consistent with other datasets.

184

185 


\subsection{Analytical approach}

188 Descriptive summary statistics and correlation analyses were performed using $t$-tests, $\chi^{2}$ tests, and Pearson's correlation. For spatial analysis, heat maps were created using a kernel density estimation $(\mathrm{KDE})$ to examine clustering patterns of the major construction and noise complaints over time. Generalized linear mixed effects models were developed to test the year fixed-effect the effect of construction activity, while controlling for neighborhood-level random effects, with census dissemination area acting as neighborhoods (Eq. 1 in Suppl.). We also tested the effect of after-hours by adding the interaction term between construction activities and after-hours reporting. Variables entered into the interaction term were centered at the mean of the distribution. All the data points were spatially joined based on the census dissemination area (DA), which served as a random cluster variable. Noise complaints measures had Poisson distribution (Figure S5); therefore, a log-link function was used. For parameter estimation, maximum likelihood estimator and bootstrapped confidence interval were used. In order to check robustness of our results, additional regressions with the same specification were performed using only data of noise complaints reported during permitted and non-permitted hours. All analyses and mapping were performed using R version 3.4.2 (R Development Core Team, 2014).

\section{RESULTS}

205

\subsection{Descriptive summary results}

Table 1 provides a descriptive summary of the study measures. The average population density $\left(\right.$ people $/ \mathrm{km}^{2}$ ) per dissemination area $(\mathrm{DA})$ was 5,964 $(\mathrm{SD}=6,664)$. The gender was well balanced $($ female $=51 \%)$, and children $(<15$ years $)$ and seniors $(>65$ years $)$ accounted for $12 \%$ and $16 \%$, respectively. About $44 \%$ of households were living in renter occupied dwelling units, and median household income was $\$ 72,811$. In terms of other covariates, average voting rate per DA for the 2016 municipal election was 30\%, and the average number of eating and drinking places was about 3 per DA in 2016. The average level of transportation-related noise per DA was 
222 For the key variables of interest, the average major construction activities per DA per quarter

223 ranged between 0.63 and 0.83 , and the total counts have increased 76\% from 2011 to 2016

224 (Table S2). The average reports of noise complaints ranged between 1.33 and 1.48 per DA per month, and the total complaint volume has doubled from 2011 to 2016.

\subsection{Spatio-temporal patterns of construction and noise complaints}

228 Figure 1(a) illustrates the spatio-temporal patterns in major constructions in Vancouver. In 2011, 229 major constructions were concentrated in the downtown area. The construction activities appear

230 to have moved towards a southeast direction and along major commercial corridors, such as

231 Cambie Street and Oak Street. Notably, construction activities near the University of British 232 Columbia campus (far west) were consistent throughout time. Figure 1(b) shows the hotspots of 233 where noise complaints have been reported. Similar to the construction activities, the downtown 234 area has the highest volume of noise complaints. The noise complaints appear to move towards a 235 southeast direction. The complaints also tend to concentrate along several mixed-use 236 developments, such as Broadway and north of Cambie Street. These graphs show that both 237 construction activities and noise complaints have been increasing and expanding along major 238 corridors from 2011 to 2016.

\subsection{Mixed effects model results}

245 Consistent with the general spatio-temporal patterns, models generally confirmed a positive 246 relationship between major construction and noise complaints. In Table 2, both year and major 247 construction fixed effects were statistically significant at the $1 \%$ confidence level. 
253 The final model results (Model 4 in Table 2) showed that a one-unit increase in a year resulted in

254 a 7.4\% increase in monthly noise, accounting for demographic and housing-related factors

255 (Incidence rate ratio $(I R R)=1.074,95 \% \mathrm{CI}=1.049-1.098)$. Similarly, a one-unit increase in

256 construction activities resulted in a $6.2 \%$ increase in monthly noise, while holding everything

257 else in the model constant $(\mathrm{IRR}=1.062,95 \% \mathrm{CI}=1.024-1.097)$.

Results of the interaction model (Table S3) showed that there is a moderation effect of afterhours report on the association of construction activities with noise complaints. In Table S3, both the main effects for construction activities $(I R R=1.031,95 \% \mathrm{CI}=0.987-1.070)$ and after-hours reporting $(\mathrm{IRR}=1.463,95 \% \mathrm{CI}=1.339-1.586)$ were significant. The interaction term between construction activities and after-hours reporting was also highly significant (IRR $=1.050,95 \%$

$264 \mathrm{CI}=1.012-1.087)$. Figure 2 clearly shows this interaction effect. The effect of construction 265 activities on noise complaints during after-hours appears to be stronger and increasing more exponentially than regular hours.

272 In terms of the covariates, both children and elderly population are negatively associated with 273 noise complaints. For example, a one percent increase in the population 65 years and older is 274 associated with a $34 \%$ reduction in monthly noise complaints. The percentage of renter-occupied 275 homes was also negatively related to noise complaints (Model 2 in Table 2), but the coefficient 276 became statistically non-significant after adjusting for voting rate and number of proximate 277 eating/drinking places (Model 3 in Table 2). The number of eating and drinking places was 278 positively related to noise complaints, but the effect size was very small (Model 4, IRR $=1.005$, $27995 \% \mathrm{CI}=1.003-1.007)$. Interestingly, the association between voting rates and noise complaints 
was in a positive direction, but statistically insignificant. No significant relationship was found between transportation-related noise and noise complaints.

\section{DISCUSSION}

Using the longitudinal administrative data from 2011 to 2016, this study found that construction activities were associated with higher volumes of noise complaints. The results suggest that a one-unit increase in construction activity was associated with approximately a $6 \%$ higher incidence rate of noise complaints. This is one of the first studies to empirically demonstrate the association between urban development and noise annoyance. It provides evidence that construction activities are associated with increases in noise complaints. Furthermore, the significant interaction effect of construction activities and after-hours reporting implies potential issues with the current noise control and regulatory framework. The main effect of construction activities attenuated slightly when the interaction term was included in the model. However, the effect of construction activities on noise complaints seems to be stronger during after-hours than regular hours. This suggests that people are more disturbed at night due to construction activities, and that the current noise by-law in Vancouver may not be effective in protecting residents from exposure to construction noise during sleeping hours.

\section{The results remained robust after adjusting for demographic and other covariates. Presence of} proximate eating and drinking places was associated with noise complaints; however, voting rates and transportation-related noise were not significant. This suggests that transportationrelated noise may not be a strong enough driver to invoke noise complaints. In a similar vein, the results suggest that noise reporting may not be politically driven and may operate through different reporting mechanisms than other complaints (e.g. graffiti removal) that are more driven by motivations for participating in government programs (O'Brien et al., 2016). For noise complaints, past work has shown self-motivation to reduce personal harms may be stronger than other motivations (Abu-Tayeh et al., 2018). However, this statement is complicated by other research that has shown those who are economically dependent upon the noise source are less likely to report an annoyance (Miedema and Vos, 1999). More work on this aspect of noise 
311 annoyance reporting is warranted. In addition to our main findings, our study results imply that it

312 will be necessary to understand the contribution of self-interests versus public interests when

313 using crowdsourcing and social media platforms in the context of emerging smart cities and open

314 governance framework (Linders, 2012).

315

316 Our finding is consistent with previous studies of traffic- and construction-related noise. A large 317 body of work has reported a significant adverse impact of traffic noise on a variety of measures, 318 such as subjective annoyance (Michaud et al., 2005), daily activities (Pathak et al., 2008), stress 319 levels (Beutel et al., 2016; Schreckenberg et al., 2010), and sleep quality (Basner et al., 2006). 320 Although few studies exist to date that directly examined the effect of construction on noise 321 annoyance for residents, several studies have reported adverse social and economic impacts of 322 construction, leading to delays and additional costs (Gilchrist and Allouche, 2005; Matthews et 323 al., 2015; Zou et al., 2007). One study has reported that students living in a college dorm close to 324 construction sites were distracted more frequently than those living farther away ( $\mathrm{Ng}, 2000)$. 325 Another study has reported that construction activities were directly responsible for high levels 326 of annoyance by residents (Golmohammadi et al., 2013). Our study resonates with findings of 327 these earlier studies in that, of many factors contributing to noise annoyance, construction activities can be a significant source of perceived annoyance by urban residents.

330 Finally, this study provides evidence that construction noise has far reaching impacts on the general population that go beyond those experienced by workers in occupational settings. In the

332 United States and Canada, occupational health and safety regulations provide more stringent and 333 direct mechanisms for limiting construction-related noise at worksites. Currently, Canadian 334 Centre for Occupational Health and Safety (CCOHS) has established occupational exposure 335 limits for noise at worksites. For example, in British Columbia, Canada, the steady noise level 336 permitted for a full eight-hour shift is $85 \mathrm{~dB}(\mathrm{~A})$ (Canadian Centre for Occupational Health and 337 Safety, 2018). Previous research on occupational health and hygiene have reported negative 338 impacts of construction noise on workers' health (Fernández et al., 2009; Golmohammadi et al., 339 2013; Lee et al., 2015; Li et al., 2016; Neitzel et al., 2011; Seixas et al., 2012; Xiao et al., 2016). 340 A comprehensive review of construction-related noise studies has also reported that average 
341 daily noise exposure levels in most construction sites were usually above the permitted level

342 (Suter, 2002).

344 In contrast with the extensive research on construction noise in occupational settings, potential

345 health effect of construction noise on the general population has been limited, due to lack of 346 available data on neighborhood noise and perceived annoyance. However, thanks to recent

347 advances in 'big data' analytics (Mooney and Pejaver, 2018), it is now possible to use a vast

348 array of new data sources linking traditional and non-traditional data to answer complex 349 questions related to urban development pressures on population and environmental health 350 (Vlahov et al., 2007; Zou et al., 2007). For example, low cost sensors are now available for 351 collecting granular noise data in real time, and such new data sources will likely transform our 352 understanding of how noise is generated and will change the way we manage urban noise 353 problem in the 21 st century (Park et al., 2014). Through the novel use of crowdsourced noise 354 complaints in conjunction with historical archives of major construction data, this study contributes to this emerging body of research using crowdsourced data to uncover noise-related

356 health issues (Duncan et al., 2016; Tamura et al., 2017). Further research leveraging similar 357 crowdsourced data through the 311 system readily available in many cities (Butterfield, 2006) 358 will help inform future policies and programs aimed at monitoring and managing urban noise 359 pollution.

\section{Limitations and strengths}

362 Despite its ability to provide new insights, 311 data have important limitations that must be 363 considered. One limitation is related to the use of noise complaints as a measure of noise 364 annoyance. It is possible that noise complaints only represent the extreme case of noise annoyance. More work would be needed to determine how well noise complaints are correlated

366 with noise annoyance using a more traditional measure (International Organization for

367 Standardization, 2003). Another limitation has to do with the fact that little is known about the 368 demographics of the populations that use 311 services. If the population of 311 users does not 369 reflect the broader population, there will be a bias in the information presented to governments. 370 Similar issues are dealt with in research that utilizes social media data (e.g. Twitter data), where 371 the sample of users is not considered to be representative of the broader population (Mislove et 
372 al., 2011; Smith and Brenner, 2012). A third limitation is that, unlike social media data, it is not

373 possible to link 311 data back to individuals (Minkoff, 2016), making it difficult to know if

374 certain users are disproportionately affecting the types and volume of calls being made through

375 the service. This "squeaky wheel" problem is important, as a small number of highly motivated

376 residents can lead to a large number of observations in the dataset. Although our data were not

377 subject to such biases (Figure S2), the possibility of over-reporting in crowdsourced data may

378 present some challenges in using them for real-time noise surveillance. However, the increasing

379 popularity and availability of crowdsourced platforms will help make data collection processes

380 more transparent and democratic, eventually leading to reducing biases in the data (Clark et al.,

381 2016; Liu, 2017). Lastly, it was assumed that the reporting time recorded in the 311 data

382 represents relatively well the actual time of noise being heard and reported. However, there could

383 be a time lag in the noise reporting process, which might have affected the model results

384 stratified by reporting time. Even with these drawbacks, 311 data provide an additional data

385 source that can be used to better understand the location and timing of issues faced by urban

386 residents. As was done in the analysis presented in this paper, using 311 data to identify signals

387 where there may be potential problems can be a useful first step that leads to local investigations,

388 and ultimately, tangible shifts in policy.

389

390

Policy implications and takeaways

391 An important takeaway of this study is that construction-related noise could be more serious at

392 night and during sleeping hours even in the presence of noise limiting regulations and zoning

393 codes. The seriousness of after-hours construction noise was also confirmed by a recent New

394 York City study, where the actual noise sensor data provided quantitative evidence for $94 \%$ of all

395 after-hours construction complaints (Bello et al., 2018). Although many large cities have noise

396 by-laws, developers may get away with these regulations if the benefits of early completion far

397 outweigh the costs associated with paying the noise by-law exemption fees. A cursory search of

398 these exemptions in major cities in North America (U.S. and Canada) indicates that the exception

399 fees typically range between $\$ 0$ and $\$ 500$ (Table S4). Because completing the project ahead of

400 the schedule (or catching up after expensive delays) can significantly reduce construction costs

401 (Meng and Gallagher, 2012), the additional costs of exemption fees may not be seen as a

402 significant barrier to most developers. To our knowledge, no studies have directly examined the 
403 effectiveness of noise bylaws and exemption fee structures in controlling construction-related 404 noise in urban areas. Future research should examine the effectiveness of various noise by-laws 405 and abatement policies and whether exemption fees act as sufficient deterrents to after-hours 406 construction activities that are more prone to generate noise problems in rapidly growing cities.

\section{CONCLUSIONS}

410

411 This study found associations of construction activities with noise complaints. It also provided

412 evidence that the impact of construction activities on noise complaints may be stronger during

413 after-hours than regular hours. These results imply that the existing noise by-laws may not be

414 effective in restricting construction activities at night and during sleeping hours, which were

415 found to have harmful effects on sleep quality and related health effects (Halperin, 2014;

416 Hammer et al., 2013; Hume, 2010; Xiao et al., 2016; Zou et al., 2007). Although construction

417 activities can be considered as a sign of a healthy economy (Garcia-Milà and McGuire, 1992;

418 Glaeser et al., 2006), this study calls for deeper understanding of both positive and negative

419 aspects of development on the quality of life and wellbeing of urban residents. Underestimation

420 of potential negative impacts of urban development may help justify large construction projects,

421 which could come at the expense of health and wellbeing of nearby residents and potentially

422 vulnerable populations at greater health risks. Future studies should build on our findings to

423 examine connections between urban development and perceived levels of noise pollution,

424 ultimately linking actual health-related outcomes, including but not limited to, sleep deficiency, 425 stress, and mental health. 


\section{REFERENCES}

Abu-Tayeh G, Neumann O, Stuermer M, 2018, "Exploring the Motives of Citizen Reporting Engagement: Self-Concern and Other-Orientation" Business \& Information Systems Engineering 60(3) 215-226

Adams M, Cox T, Moore G, Croxford B, Refaee M, Sharples S, 2006, "Sustainable Soundscapes: Noise Policy and the Urban Experience" Urban Studies 43(13) 2385-2398

Basner M, Babisch W, Davis A, Brink M, Clark C, Janssen S, Stansfeld S, 2014, "Auditory and non-auditory effects of noise on health" The Lancet 383(9925) 1325-1332

Basner M, Samel A, Isermann U, 2006, "Aircraft noise effects on sleep: application of the results of a large polysomnographic field study" The Journal of the Acoustical Society of America 119(5 Pt 1) 2772-84

Bello J P, Silva C, Nov O, DuBois R L, Arora A, Salamon J, Mydlarz C, Doraiswamy H, 2018, "SONYC: A System for the Monitoring, Analysis and Mitigation of Urban Noise Pollution" Communications of the ACM, http://arxiv.org/abs/1805.00889

Belojević G, Jakovljević B, Aleksić O, 1997, "Subjective reactions to traffic noise with regard to some personality traits" Environment International 23(2) 221-226

Berglund B, Lindvall T, Schwela D H, 1999, "Guidelines for community noise"

Beutel M E, Jünger C, Klein E M, Wild P, Lackner K, Blettner M, Binder H, Michal M, Wiltink J, Brähler E, Münzel T, 2016, "Noise Annoyance Is Associated with Depression and Anxiety in the General Population- The Contribution of Aircraft Noise" PloS one 11(5) $\mathrm{e} 0155357$

Butterfield E, 2006, "311 Systems Come of Age" Washington Technology

Canadian Centre for Occupational Health and Safety, 2018, "Noise - Occupational Exposure Limits in Canada" OSH Answers Fact Sheets, https://www.ccohs.ca/oshanswers/phys_agents/exposure_can.html

City of Vancouver, 2016, "Noise Control Bylaw 6555", Canada, http://former.vancouver.ca/bylaws/6555c.PDF

City of Vancouver, 2017a, "2017 By-election Municipal Election Official Results" Municipal Elections, http://data.vancouver.ca/datacatalogue/municipalElectionResults.htm

City of Vancouver, 2017b, "3-1-1 case location details" Open data catalogue, http://data.vancouver.ca/datacatalogue/311 caseVolume.htm

Clark B Y, Zingale N, Logan J, Brudney J, 2016, "A Framework for Using Crowdsourcing in Government" International Journal of Public Administration in the Digital Age 3(4) 57-75

Davies H, Van Kamp I, 2012, "Noise and cardiovascular disease: A review of the literature 2008-2011" Noise \{\&\} Health 14(61) 287

DMTI, 2016, "CanMap. Content Suite Data Dictionary 2016.3 Release"

Duncan D T, Tamura K, Regan S D, Athens J, Elbel B, Meline J, Al-Ajlouni Y A, Chaix B, 2016, "Quantifying Spatial Misclassification in Exposure to Noise Complaints Among Low-Income Housing Residents Across New York City Neighborhoods: A Global Positioning System (GPS) Study" Annals of Epidemiology 27(1) 67-75

Dye C, 2008, "Health and Urban Living" Science 319(5864) 766-769

Eriksson C, Hilding A, Pyko A, Bluhm G, Pershagen G, Östenson C-G, 2014, “Long-term aircraft noise exposure and body mass index, waist circumference, and type 2 diabetes: a prospective study" Environmental health perspectives 122(7) 687-694

Fernández M D, Quintana S, Chavarría N, Ballesteros J A, 2009, "Noise exposure of workers of 
the construction sector" Applied Acoustics 70(5) 753-760

Garcia-Milà T, McGuire T J, 1992, “The contribution of publicly provided inputs to states' economies" Regional Science and Urban Economics 22(2) 229-241

Gilchrist A, Allouche E N, 2005, "Quantification of social costs associated with construction projects: state-of-the-art review" Tunnelling and Underground Space Technology 20(1) 89104

Glaeser E L, Gyourko J, Saks R E, 2006, "Urban growth and housing supply" Journal of Economic Geography 6(1) 71-89

Golmohammadi R, Mohammadi H, Bayat H, Habibi Mohraz M, Soltanian A R, 2013, "Noise annoyance due to construction worksites." Journal of research in health sciences $13(2)$ 201-7

Hajnal Z L, Lewis P G, 2003, "Municipal Institutions and Voter Turnout in Local Elections" Urban Affairs Review 38(5) 645-668

Hall D A, Irwin A, Edmondson-Jones M, Phillips S, Poxon J E W, 2013, “An exploratory evaluation of perceptual, psychoacoustic and acoustical properties of urban soundscapes" Applied Acoustics 74(2) 248-254

Halperin D, 2014, "Environmental noise and sleep disturbances: A threat to health?" Sleep Science 7(4) 209-212

Hammer M S, Swinburn T K, Neitzel R L, 2013, "Environmental noise pollution in the United States: Developing an effective public health response" Environmental Health Perspectives 122(2) 115-119

Hammersen F, Niemann H, Hoebel J, 2016, "Environmental noise annoyance and mental health in adults: Findings from the cross-sectional German health update (GEDA) study 2012" International Journal of Environmental Research and Public Health 13(10) 1-12

Hoeger R, Schreckenberger D, Felscher-Suhr U, Griefahn B, 2002, "Night-time noise annoyance: State of the art" Noise and Health 4(15) 19-25

de Hollander A E M, Staatsen B A M, 2003, "Health, environment and quality of life : an epidemiological perspective on urban development" Landscape and Urban Planning $6553-$ 62

Hume K, 2010, "Sleep disturbance due to noise:Current issues and future research" Noise and Health 12(47) 70

International Organization for Standardization, 2003, "ISO/TS 15666:2003 Acoustics -Assessment of Noise Annoyance by Means of Social and Socio-acoustic Surveys"

Ising H, Kruppa B, 2004, "Health effects caused by noise: evidence in the literature from the past 25 years" Noise \& health 6(22) 5-13

Jakovljevic B, Paunovic K, Belojevic G, 2009, "Road-traffic noise and factors influencing noise annoyance in an urban population" Environment International 35(3) 552-556

Jarup L, Dudley M-L, Babisch W, Houthuijs D, Swart W, Pershagen G, Bluhm G, Katsouyanni K, Velonakis M, Cadum E, Vigna-Taglianti F, HYENA Consortium, 2005, "Hypertension and Exposure to Noise near Airports (HYENA): study design and noise exposure assessment" Environmental health perspectives 113(11) 1473-8

Knall V, Schuemer R, 1983, "The differing annoyance levels of rail and road traffic noise" Journal of Sound and Vibration 87(2) 321-326

Lawton R N, Fujiwara D, 2016, "Living with aircraft noise: Airport proximity, aviation noise and subjective wellbeing in England" Transportation Research Part D: Transport and Environment 42 104-118 
Lee S C, Hong J Y, Jeon J Y, 2015, "Effects of acoustic characteristics of combined construction noise on annoyance" Building and Environment 92 657-667

Li X, Song Z, Wang T, Zheng Y, Ning X, 2016, "Health impacts of construction noise on workers: A quantitative assessment model based on exposure measurement" Journal of Cleaner Production 135 721-731

Linders D, 2012, "From e-government to we-government: Defining a typology for citizen coproduction in the age of social media" Government Information Quarterly 29(4) 446-454

Liu H K, 2017, "Crowdsourcing Government: Lessons from Multiple Disciplines" Public Administration Review

Lovgreen T, 2017, “'Just constant noise': residents upset over city-approved construction racket at 5 a.m." $C B C$ News, http://www.cbc.ca/news/canada/british-columbia/overnightconstruction-keeps-residents-up-1.4140335

Matthews J C, Allouche E N, Sterling R L, 2015, "Social cost impact assessment of pipeline infrastructure projects" Environmental Impact Assessment Review 50 196-202

Meng X, Gallagher B, 2012, "The impact of incentive mechanisms on project performance" International Journal of Project Management 30(3) 352-362

Michaud D, Keith S, McMurchy D, 2005, "Noise annoyance in Canada" Noise \& health 7(27) 39-47

Miedema H M E, Vos H, 1999, "Demographic and attitudinal factors that modify annoyance from transportation noise" The Journal of the Acoustical Society of America 105(6) 33363344

Minkoff S L, 2016 NYC 311: A Tract-Level Analysis of Citizen-Government Contacting in New York City

Mislove A, Lehmann S, Ahn Y, Onnela J, Rosenquist J N, 2011, "Understanding the Demographics of Twitter Users", in Proceedings of the Fifth International AAAI Conference on Weblogs and Social Media, pp 554-557

Mooney S J, Pejaver V, 2018, "Big Data in Public Health: Terminology, Machine Learning, and Privacy" Annual Review of Public Health 39(1) 95-112

Neitzel R L, Stover B, Seixas N S, 2011, "Longitudinal Assessment of Noise Exposure in a Cohort of Construction Workers" The Annals of Occupational Hygiene 55(8) 906-916

$\mathrm{Ng} \mathrm{C} \mathrm{F,} \mathrm{2000,} \mathrm{"Effects} \mathrm{of} \mathrm{building} \mathrm{construction} \mathrm{noise} \mathrm{on} \mathrm{residents:} \mathrm{A} \mathrm{quasi-experiment"} \mathrm{Journal}$ of Environmental Psychology 20(4) 375-385

O’Brien D T, Offenhuber D, Baldwin-Philippi J, Sands M, Gordon E, 2016, “Uncharted Territoriality in Coproduction: The Motivations for 311 Reporting" Journal of Public Administration Research and Theory 27(2) 320-335

O'Brien D T, Sampson R J, Winship C, 2015, "Ecometrics in the Age of Big Data" Sociological Methodology 45(1) 101-147

Offenhuber D, 2015, "Infrastructure legibility - a comparative analysis of open311-based citizen feedback systems" Cambridge Journal of Regions, Economy and Society 8(1) 93-112

Ohrström E, Björkman M, Rylander R, 1988, "Noise annoyance with regard to neurophysiological sensitivity, subjective noise sensitivity and personality variables" Psychological medicine 18(3) 605-13

Orban E, McDonald K, Sutcliffe R, Hoffmann B, Fuks K B, Dragano N, Viehmann A, Erbel R, Jöckel K-H, Pundt N, Moebus S, 2016, "Residential Road Traffic Noise and High Depressive Symptoms after Five Years of Follow-up: Results from the Heinz Nixdorf Recall Study" Environmental health perspectives 124(5) 578-85 
Park T H, Turner J, Musick M, Lee J H, Jacoby C, Mydlarz C, Salamon J, 2014, "Sensing urban soundscapes" CEUR Workshop Proceedings 1133(c) 375-382

Passchier-Vermeer W, Passchier W F, 2000, "Noise exposure and public health" Environmental health perspectives 108 Suppl 123-31

Pathak V, Tripathi B D, Mishra V kumar, 2008, "Evaluation of traffic noise pollution and attitudes of exposed individuals in working place" Atmospheric Environment 42(16) 38923898

Province of British Columbia, 2017, "BC Major Projects Inventory", https://www2.gov.bc.ca/gov/content/employment-business/economicdevelopment/industry/bc-major-projects-inventory/recent-reports

R Development Core Team, 2014, "A language and environment for statistical computing”, http://www.r-project.org

Recio A, Linares C, Banegas J R, Díaz J, 2016, "Road traffic noise effects on cardiovascular, respiratory, and metabolic health: An integrative model of biological mechanisms" Environmental Research 146 359-370

Saremi M, Grenèche J, Bonnefond A, Rohmer O, Eschenlauer A, Tassi P, 2008, "Effects of nocturnal railway noise on sleep fragmentation in young and middle-aged subjects as a function of type of train and sound level" International Journal of Psychophysiology 70(3) 184-191

Schmidt F P, Basner M, Kröger G, Weck S, Schnorbus B, Muttray A, Sariyar M, Binder H, Gori T, Warnholtz A, Münzel T, 2013, "Effect of nighttime aircraft noise exposure on endothelial function and stress hormone release in healthy adults" European heart journal 34(45) 3508-14a

Schreckenberg D, Griefahn B, Meis M, 2010, “The associations between noise sensitivity, reported physical and mental health, perceived environmental quality, and noise annoyance" Noise \& health 12(46) 7-16

Seixas N S, Neitzel R, Stover B, Sheppard L, Feeney P, Mills D, Kujawa S, 2012, "10-Year prospective study of noise exposure and hearing damage among construction workers" Occupational and Environmental Medicine 69(9) 643-650

Shepherd D, Welch D, Dirks K N, Mathews R, 2010, "Exploring the relationship between noise sensitivity, annoyance and health-related quality of life in a sample of adults exposed to environmental noise" International Journal of Environmental Research and Public Health 7(10) 3579-3594

Simpson M, Bruce R, 1981, "Noise in America: Extent of the Noise Problem. (Report 550/9-81101)", Washington, D.C.

Smith A, Brenner J, 2012, “Twitter Use 2012", Washington, D.C

Sørensen M, Hvidberg M, Hoffmann B, Andersen Z J, Nordsborg R B, Lillelund K G, Jakobsen J, Tjønneland A, Overvad K, Raaschou-Nielsen O, 2011, "Exposure to road traffic and railway noise and associations with blood pressure and self-reported hypertension: a cohort study" Environmental Health 10(1) 92

Stansfeld S A, Haines M M, Burr M, Berry B, Lercher P, 2000, "A Review of Environmental Noise and Mental Health." Noise \& health 2(8) 1-8

Statistics Canada, 2017, "Vancouver, CY [Census subdivision], British Columbia and Greater Vancouver, RD [Census division], British Columbia (table). Census Profile" Statistics Canada Catalogue No. 98-316-X2016001, https://www12.statcan.gc.ca/censusrecensement/2016/dp-pd/prof/index.cfm?Lang=E 
Suter A H, 2002, "Construction Noise: Exposure, Effects, and the Potential for Remediation; A Review and Analysis" AIHA Journal 63(6) 768-789

Tamura K, Elbel B, Chaix B, Regan S D, Al Y A, Jessica A, Julie K A, Duncan D T, 2017, "Residential and GPS-Defined Activity Space Neighborhood Noise Complaints, Body Mass Index and Blood Pressure Among Low- Income Housing Residents in New York City" Journal of Community Health 42(5) 974-982

The Atlantic, 2018, "City Noise Might Be Making You Sick” The Atlantic (2/20/2018)

The Canadian Press, 2016, "New data shows nuisance noise prompts growing complaints across Vancouver" The Canadian Press (7/12/2016)

US EPA, 1981, "Noise Effects Handbook; A Desk Reference to Health and Welfare Effects of Noise", Washington, D.C.

Vlahov D, Freudenberg N, Proietti F, Ompad D, Quinn A, Nandi V, Galea S, 2007, "Urban as a Determinant of Health" Journal of Urban Health 84(S1) 16-26

Wandersman A, Nation M, 1998, "Urban neighborhoods and mental health: Psychological contributions to understanding toxicity, resilience, and interventions." American Psychologist 53(6) 647-656

Xiao J, Li X, Zhang Z, 2016, "DALY-Based Health Risk Assessment of Construction Noise in Beijing, China" International Journal of Environmental Research and Public Health 13(11) 1045

Zou P X W, Zhang G, Wang J, 2007, "Understanding the key risks in construction projects in China" International Journal of Project Management 25(6) 601-614 


\section{A: Construction}

\section{1}

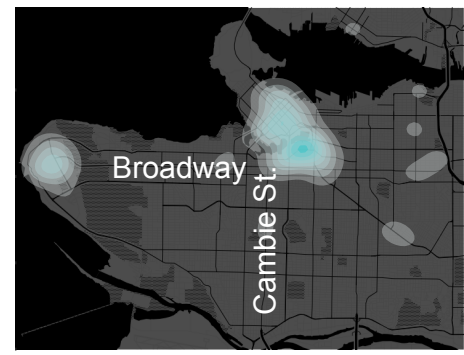

2014

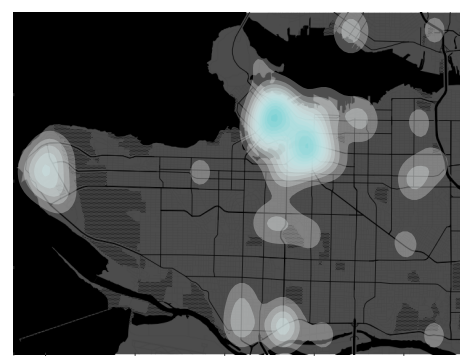

\section{B: Noise}

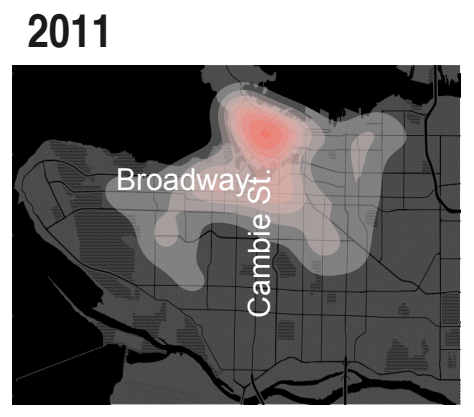

2014

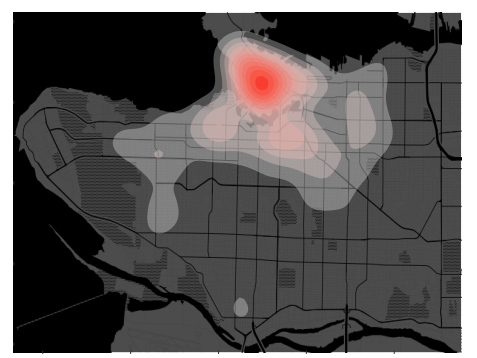

2012

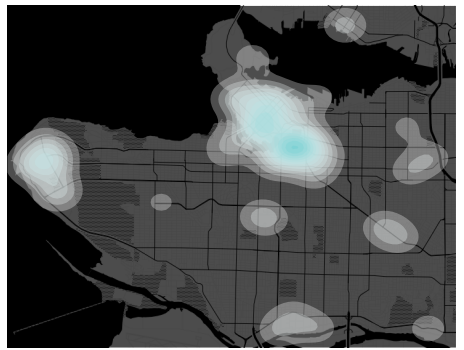

2015

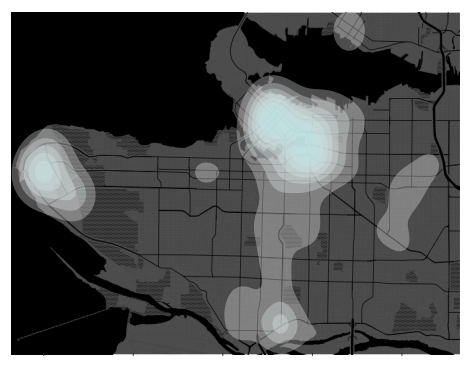

2013

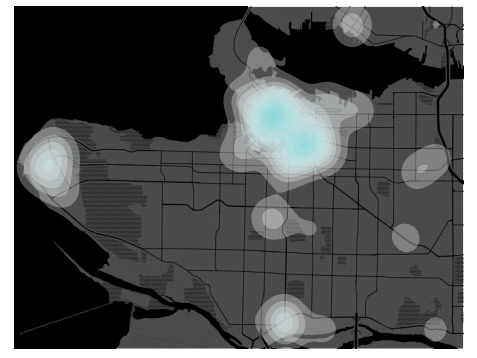

2016

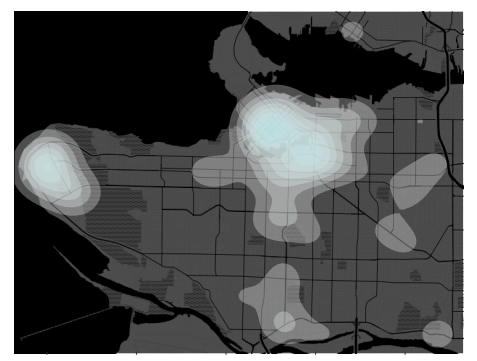

Low

density

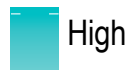

density

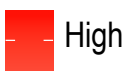

\section{6}

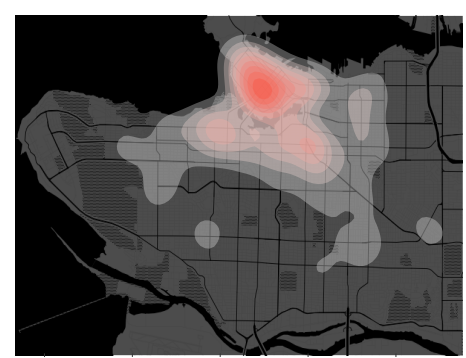

2013

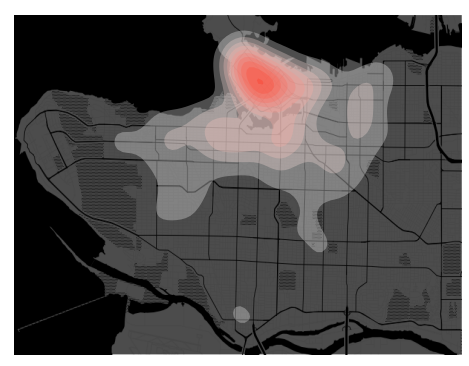

\section{5}
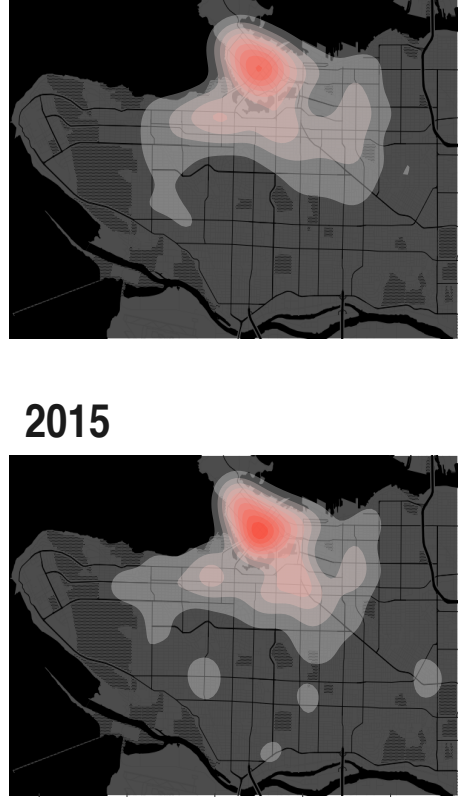

Figure 1. Spatio-temporal patterns of (a) major constructions and (b) noise complaints by year in Vancouver, Canada (2011-2016) 


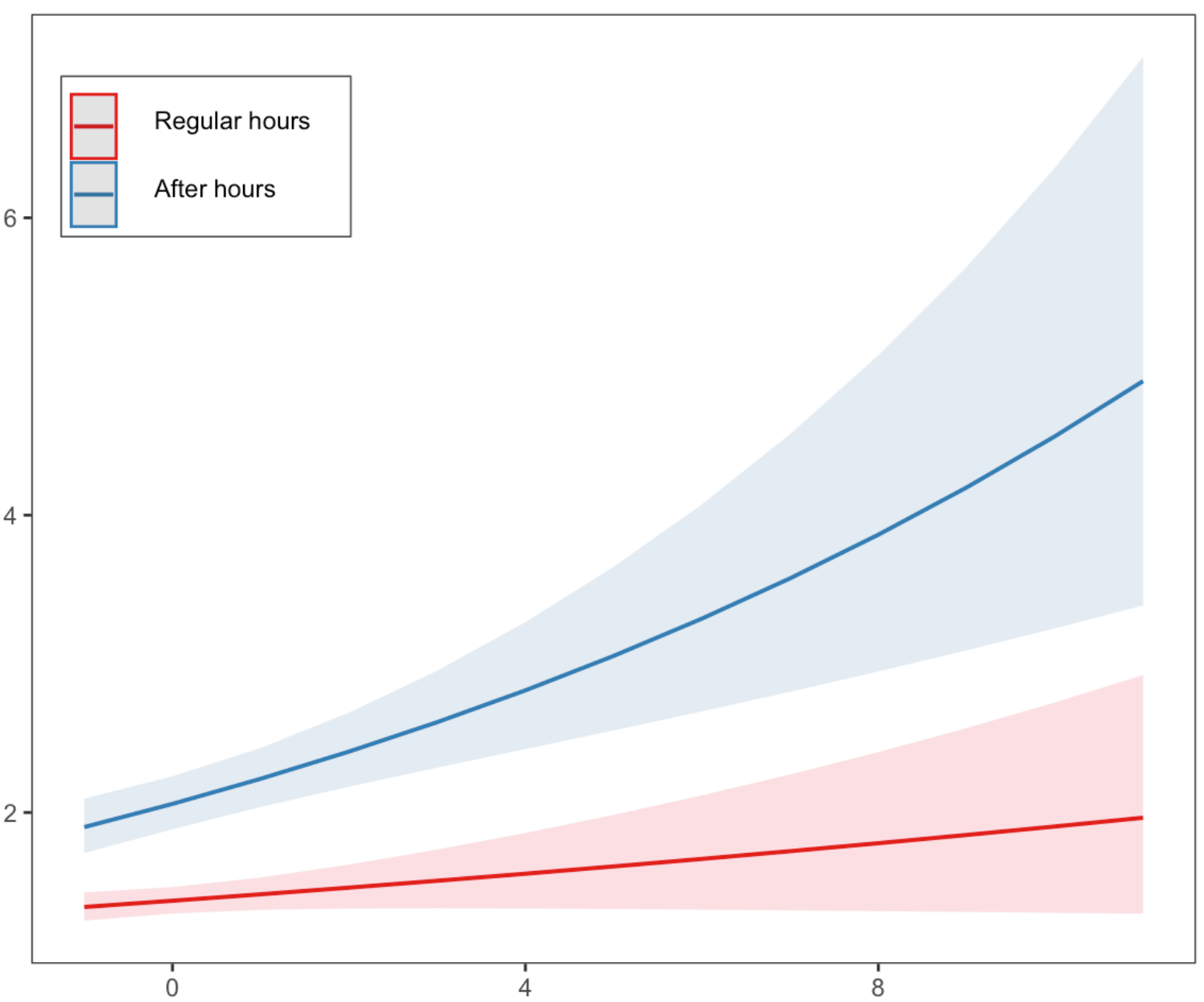

3 Figure 2. Effect of interaction between construction activities and after-hours reporting on noise 4 complaints in Vancouver, Canada (2011 - 2016).

6 Note: The permitted (regular) hours for construction activities are: 7:30am - 8pm (M-F) and 10am - 8pm (Sa) 7 for private properties; 7:30am - 8pm (M-Sa) and 10am - 8pm (Su \& holidays) for city streets. The interaction 8 effect was plotted by holding covariates constant at their mean values. 
Table 1. Descriptive summary of demographic and covariate measures

\begin{tabular}{|c|c|c|}
\hline Variables & $\begin{array}{l}\text { Mean or \% (SD) } \\
(\mathrm{N}=1,654)\end{array}$ & Data sources \\
\hline \multicolumn{3}{|l|}{ Demographics } \\
\hline Population density (people/km²) & & Canadian Census 2016 \\
\hline Mean (SD) & $5,964(6,664)$ & \\
\hline Missing & & \\
\hline Female population (\% of total) & & Canadian Census 2016 \\
\hline Mean (SD) & $51 \%(4 \%)$ & \\
\hline Missing & 3 & \\
\hline Children $<15$ years $(\%$ of total) & & Canadian Census 2016 \\
\hline Mean (SD) & $12 \%(5 \%)$ & \\
\hline Missing & 7 & \\
\hline Seniors $>65$ years $(\%$ of total) & & Canadian Census 2016 \\
\hline Mean (SD) & $16 \%(8 \%)$ & \\
\hline Missing & 4 & \\
\hline \multicolumn{3}{|l|}{ Household-related measures } \\
\hline Median household income & & Canadian Census 2016 \\
\hline Mean (SD) & $\$ 72,811(\$ 24,926)$ & \\
\hline Missing & 4 & \\
\hline Percentage of renter-occupied homes & & Canadian Census 2016 \\
\hline Mean (SD) & $44 \%(22 \%)$ & \\
\hline Missing & 4 & \\
\hline \multicolumn{3}{|l|}{ Other covariates } \\
\hline Voting rate & $30 \%(5 \%)$ & 2017 municipal election* \\
\hline \# of eating/drinking places & $3.03(9.04)$ & 2016 DMTI EPOI $^{*}$ \\
\hline Transportation-related noise $(\mathrm{dB}(\mathrm{A}))$ & $63.56(3.85)$ & Gan et al, 2012 \\
\hline
\end{tabular}

Note: Unit of analysis is dissemination area (DA); *Data sources are 2016 Canadian Census, 2017 Municipal election results, 2016 DMTI Enhanced Point of

Interest data, and annual day-evening-night A-weighted equivalent continuous noise levels (Lden dB(A)) from Gan et al, 2012. 
Table 2. Associations of construction activities with all noise complaints in Vancouver, Canada (2011 - 2016)

\begin{tabular}{|c|c|c|c|c|}
\hline & & Dependent $V$ & e: Noise complaints & \\
\hline & Model 1 & Model 2 & Model 3 & Model 4 \\
\hline & $\operatorname{IRR}(95 \% \mathrm{Cl})$ & IRR $(95 \% \mathrm{Cl})$ & IRR $(95 \% \mathrm{Cl})$ & IRR (95\% CI) \\
\hline Year & $1.073^{\star * \star}(1.052,1.096)$ & $1.074^{\star \star \star}(1.052,1.098)$ & $1.074^{* * *}(1.051,1.098)$ & $1.074^{* * *}(1.049,1.098)$ \\
\hline Major constructions & $1.071^{* * *}(1.029,1.105)$ & $1.067^{\star * *}(1.031,1.099)$ & $1.059^{* * *}(1.023,1.091)$ & $1.062^{* * *}(1.024,1.097)$ \\
\hline Population density & & $1.000^{*}(1.000,1.000)$ & $1.000(1.000,1.000)$ & $1.000(1.000,1.000)$ \\
\hline$\%$ Female & & $1.008(0.279,4.157)$ & $1.417(0.421,4.541)$ & $1.527(0.380,5.086)$ \\
\hline$\%$ Children $(<15 \mathrm{yr})$ & & $0.021^{* * *}(0.003,0.128)$ & $0.117^{* *}(0.020,0.645)$ & $0.151^{* *}(0.020,0.838)$ \\
\hline$\%$ Seniors (> 65 yr) & & $0.194^{* * *}(0.093,0.407)$ & $0.341^{* * *}(0.163,0.663)$ & $0.386^{* *}(0.184,0.789)$ \\
\hline Median household income & & $1.000(1.000,1.000)$ & $1.000(1.000,1.000)$ & $1.000(1.000,1.000)$ \\
\hline$\%$ Renter occupied homes & & $0.596^{* *}(0.373,0.943)$ & $0.700(0.456,1.061)$ & $0.718(0.451,1.165)$ \\
\hline Voting rate & & & $1.034(0.335,2.883)$ & $1.178(0.352,3.598)$ \\
\hline$\#$ of eating and drinking places & & & $1.005^{\star * *}(1.003,1.008)$ & $1.005^{\star * *}(1.003,1.007)$ \\
\hline Transportation-related noise & & & & $1.014(0.996,1.032)$ \\
\hline Random Effect & & & & \\
\hline \# of Dissemination Area & 119 & 118 & 115 & 114 \\
\hline Dissemination Area Variance & 0.063 & 0.036 & 0.023 & 0.022 \\
\hline $\mathrm{N}$ & 2,020 & 2,011 & 1,996 & 1,964 \\
\hline Log Likelihood & $-3,054$ & $-3,024$ & $-2,996$ & $-2,948$ \\
\hline AlC & 6,116 & 6,069 & 6,015 & 5,922 \\
\hline $\mathrm{BIC}$ & 6,139 & 6,125 & 6,082 & 5,995 \\
\hline
\end{tabular}

